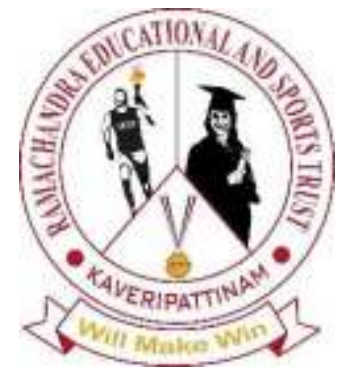

Recent trends in Management and Commerce

Vol: 2(3), 2022

REST Publisher

ISBN: 978-81-936097-6-7

Website: http://restpublisher.com/book-series/rmc/

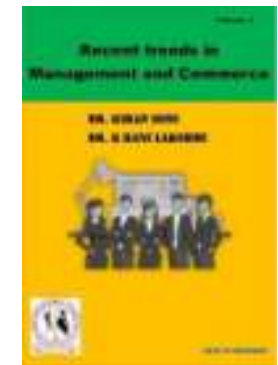

\title{
Green Supply Chain Management; with Dematel MCDM Analysis
}

\author{
Kurinjimalar Ramu, Dr. M. Ramachandran, M. Nathiya, M. Manjula \\ REST Labs, Kveripattinam, Krishnagiri, Tamil Nadu, India. \\ Email: kurinjimalar@restlabs.in
}

\begin{abstract}
Demodel Causation between the components of a system and the result is a type Useful for analysis Structural model approach relationships. Vague dematal, Green supply chain management Testing and evaluation of results, critical success factors, analytics network process dematal are one of the components Can be used to Ensure relationship / interdependence or Comparison of relationships in the decision-making test between them Reflect the size. And Appraisal Laboratory (Dimadel) of a complex system Cause-effect chain element considered a better method to identify. It is the evaluation and visual structure of the interrelated relationships between factors Deals with identifying important ones by Sample. Over the past decade, the use of dimethoate numerous studies have been conducted on. Various variations have also been proposed in the literature. The purpose of this study is démodé Methods and applications of the technique Is to systematically review. Used According to the approaches publications five categories: Compiled Classical Dimetal Fuzzy Blur, Gray Blur, Analysis Network Process- (anp-) blur and other blur. All documents are summarized and analyzed for each category. Point out their implementation practices, actual applications and important innovations. This systematic and comprehensive review of current research trends and Contains Researchers on the use of tomato and Valuable insights for coaches and more Indicate possible directions for research.
\end{abstract}

\section{Introduction}

In this study, the causal relationship of accidents to construction processes an ambiguous dematal method is used to estimate. This combination is applied to the inaccuracy and subjectivity of human judgments. Interval packages rather than real numbers in ambiguous summation theory Are used. Linguistic words are transformed into obscure numbers Because of the green supply chain environmental pollution and Reduce production costs, and more It will stimulate economic growth. Greater customer satisfaction, Competition based on positive image and reputation Creates benefits and their products Provides excellent opportunity for export. System of pro-environmental countries is complex and It is proposed to study and solve knit problem groups because it verifies the variables between Interdependence and Attempts to improve them by providing a specific chart. Important success factors or csfs, a purpose within a project or task Indicators of opportunities, activities or conditions required to be achieved. Key Success Factors (csf) vary for each company and current and Here are some important Success Factor Examples customers market share with Increase existing our customers working when Be service oriented online process improvement Achieve order fulfillment excellence. Important success factors are strategically measured where as important success measures are key performance indicators measured in terms of size. Analysis Network Process (anp) is multi-dimensional Is the principle of measurement, which is complete from individual judgments Used to obtain comparative priority quantities of numbers (Or actual measurements normalized to the comparative form).Analysis Network Process (anp) Used in multi-level results analysis Is the most common form of hierarchical process (anp). Both are then paired to measure the weight of the components of the structure Use the method of comparisons, which can eventually sort the alternatives.

\section{Fuzzy Dematel}

Demonstrates how the company used our proposed ambiguous dematal Skill development of their global managers Evaluate eight iqs for better execution Method for doing and classifying. Therefore, we have proposed a vague dematol method for achieving the segmentation of skills required to better implement the Skill development of managers worldwide. Our proposed method is, Using both linguistic variables and ambiguous integration methods successfully expands the digital system, and thus effectively dealing with ambiguous and inaccurate judgments can. In particular, the proposed method is a set of factors of complexity and a causal group Can successfully divide the effect group and create a visible cause map. With a causal diagram, it is easy to Capture the problem of a problem, Thus being able to make profound decisions. The vague dematerialization system proposed by $\mathrm{s}$ is comprehensive and complex Issues that the team must decide in ambiguous contexts to differentiate between factors Applies to all companies facing. [1].Ambiguous dimple In the original timetable, the factors that make up the decision to install a configuration model Relationships are valued by crisp values. However, in many real-world applications, human ratings are mostly human Estimates are often unclear and accurate numerical values Is 
not sufficient to estimate the ambiguous relationship between the criteria. The ambiguous dematal sheets identified in this literary study are listed in Table 2 for ease of reading and comprehension. are compressed. The Dis Table also provides a classification of such sheets based on the different purposes for which the ambiguous dreamt is used. Generally, two types of ambiguous dimetal models are presented in the literature, viz [2]. Dematel cannot be used directly to identify csfs associated with emergency success. Therefore, the set of intuitive ambiguities Vague regarding the subjective judgments of human beings can be implemented to measure emotions. Then, the vague judgments of the experts can be changed to ifns. Besides, the opinions of experts should be coordinated for panel decision making. Since the expression pattern of the paddle and the bow are identical, the intuition is of obscure numbers Introduced concepts and arithmetic functions, in short, ifns [3]. There is still a lack of level support to understand Key factors. Next, make an impact on service innovations in manufacturing companies this paper uses the vague dematel method to analyze the structured size of factors. In fact, in the second section, it affects the layout of the first of the obscure demodal system the step was completed with the aim of identifying problems and factors. Through a literary study and organizational research, this study summarizes the factors that influence the service innovations of manufacturing companies. Factors influencing service innovation in manufacturing companies in general are interrelated and mutually influential. And to distinguish these factors from cause for these study managers other factors help to determine which factors are triggering. Managers can easily achieve service innovations by focusing on the most important impact factors [4].Advantages of using dematel and anp methods Well described, dematel is cause-effect Is a great way to analyze relationships, There may be criteria put forward and the relevant structural model can be considered. However, the dematel cannot determine the weight of individual criteria, where the anp comes to hand. Assessment criteria In different and complex cases,Anp in calculating criterion priorities and their relationships Can provide benefits. Both methods are complex Provide support in dealing with issues, this is because dams can have better insights into the problems that To be resolved, and the interactions between the clusters of related factors May contain. Combining dematel and amp methods are key features of policy implementation can provide a useful tool for diagnosing and calculating the weight of business environment criteria [5]. This research originally designed a questionnaire for ambiguous dematal consisting of three parts. The first part is for easy understanding and response of experts According to the comments; the strategic blueprint for ambiguous dematol applies to many businesses that have to deal with complex criteria issues that require the use of team-decision-making in ambiguous contexts. And applies to many businesses. The present study uses the obscure demodal method to obtain a more accurate analysis [6].

\section{Green Supply Chain Management}

Green deliver chain management is the system of product design, material sourcing and choice, production approaches and shipping of the cease product to the customer, and cease-of-production control Included deliver chain management is defined as integrating environmental wondering. It's useful existence and is described as the optimization technique. In order to provide a good enough know-how Relationships between proposed gscm standards, Green supply chain management, green supply chain Management procedures, drivers outside of its implementation And enterprise performance green supply chain management distribution chain (sc) and distribution chain this chapter on control (scm) standards. The most important shown Cite one of the control trends. Supply chain manufacturers, suppliers, transporters, warehouses, the fulfillment of consumer requests, Distribution chain management is defined as a method that includes companies to customers, Aims to manipulate deliver and demand. And production from uncooked fabric buying, meeting, warehousing, inventory tracking, coordinating activities starting from order entry and control and delivery. In other phrases, deliver chain control Is from manufacturing to transport of completed products or services to customers [7]. Green supply chain management, increasing degradation of the environment has raised concerns among various researchers and academics. Therefore, many articles related to GSCM have been published over the last few years, Environmental thinking is additionally expressed in business. It is said to be an effective measure to increase the company's environmental performance and reduce environmental risks. In a recent study, gscm linked with human resource management to achieve organizational sustainability and truly sustainable distribution chains gscm. Recognized as an important part of affecting organizational sustainability in today's era of globalization, buyers with a focus on improving the environment GSCM enhances various opportunities, which not only enhances the process of greening the environment but also enhances ecoeconomic efficiency. Supply chain [8].After discussing the findings with 3 specialists at Case Company, carbon control for provider selection and valuation is taken into consideration a growing parameter for keeping a protracted-term partnership. Accordingly, the 4-step technique for carbon management of suppliers changed into approved based totally on expert reviews. In the first phase, the carbon control scorecard (cms) may be launched and within the proposed framework 13 Criteria may be similarly incorporated into the quarterly commercial enterprise assessment (qbr). In the second step by incorporating the carbon issue into the procurement rules, providers are required to make a preliminary self-evaluation at some point of the cms questionnaire. After that, the company can gain a draft understanding of carbon management abilities for its providers, a good way to help pick out unique carbon risks and prioritize them. Meanwhile, carbon control (c5) and carbon facts control systems Companies will pay close interest to two standards for schooling for (c9) and the way its green deliver chain providers are uncovered to carbon chance [9]. The deliver chain threat control literature focuses more often than not on dealing with threat from the point of view of the focus or its immediate component suppliers. Distribution chains are increasingly more issue to catastrophic activities together with the Tahoe earthquake and tsunami or the incapacity of logistics service vendors to meet call for increases for the duration of the holiday season. However, the provider's role is largely in the research of the logistics triad regarding the provider, patron and logistics service provider. This section is taken into consideration passive or slender, and we offer a quick evaluation of supply chain danger control. 3pls Sub-classification of risks faced and alertness of more than one criterion decision strategies in supply chain threat management. Our overview outcomes in a comprehensive class of risks affecting logistics service carriers [10]. Green supply chain management (gscm). The cause and effect criteria in gscm were explored and discussed. Proposed a new model for creativity evaluation in the 
context of the dematel method application. This study uses several stages of sample selection and data collection, this includes quality and quantity surveys. The dematel method was used to analyze the relationship of creativity to future restaurant space design. For comparative weights of dimensions and criteria in determining wind farm locations respectively To find the correlations between, a hybrid approach was used that combined ambiguous dreamt with analytical network process (anp) approaches [11].The last two decades have seen significant growth in Gscm, both from theoretical and experimental studies Early practical and ideological developments are different, and researchers are different They have defined gscm in different ways using words. GSCM is defined as organizational initiatives, to achieve performance goals Refers to environmental topics such as collaboration between companies E.g., Market share and financial performance) Green procurement, green production, production management integration, Green Distribution, Green Marketing and Reverse Logistics gscm to close the loop as described Gscm is material design and material selection [12]

\section{Decision Making Trial and Evaluation}

Decision-making trial and evaluation laboratory (dematel) method become first employed by way of fontal and gabs in 1976. ... Dematel grow to be extra popular technique in japan due to the fact it's far a significant technique that's able to examine and formulate all intertwined cause and effect relationships in each structural model. The proposed choice making methodology is used to investigate the inner obstacles to remanufacturing implementation. Our research crew conveyed our studies thoughts to three business managers who're hired in one-of-a-kind positions in an ordinary remanufacturer a few researchers mentioned product recuperation in engine remanufacturing and compared production and remanufacturing through the utility of diesel engine production. Developed a multi-criteria choice making (modem) model for remanufacturing, and it's miles the best take a look at that integrates the mcdm device into research on remanufacturing grey choice making trial and assessment laboratory (dematel) technique. By distinctive feature of those findings, remanufacturers can get rid of fundamental internal boundaries and might boom the chances of practicing more productive remanufacturing within the Chinese car environments [13].Decision testing and evaluation Laboratory is the concept of demat approach direct and oblique have an impact on the matrix is formed by linear transformation. Compared with dematel, fdmIn the real world scenario due to the flexible threshold function May be more healthy. In this study, fdm is the generalization approach of the dematal Uses mathematical resources to expose. As we acknowledge, the composition and interpolation results Due to the problem, one using the simple weighing technique awesome selection for exam makers is difficult. One for overcoming the above problems Way, about the implications between the criteria to get the final weight by thinking, to the standards is to obtain the facts of the vulnerabilities in between. However seeing that those standards may additionally have loop or feedback relationships [14].To calculate the quantity of interdependences and decide the extent of significance of symptoms with reference to the accomplishment of a described goal, a combination of strategies dematel and anp may be used as tools for multiple criteria choice making but, in case of numerous signs for measuring the implemented measures results and for manipulate preference making, it's miles critical to determine which of the indicators is greater huge for accomplishing a defined goal. Moreover, large huge kind of located signs and signs have interdependent effect. Implementing superb measures indoors manipulate, want to improve a hallmark rate, however affect in a different way some of other indicators' values. The considered problem represents a traditional example of more than one standards desire making [15].This have a look at makes a specialty of how stakeholders and other involved factors affect the selection making in msw control within the city regions of metro manila. There are also invaluable lessons that would be extracted from the present practices on waste generation pattern, control alternatives, resource restoration, key have an impact on factors, and different elements that could contribute to the brand new ecological strong waste control act with vital processes [16].Decision-making testing and Evaluation laboratory) method explains interrelations amongst standards, famous the relevant standards Represent the performance of factors / factors Avoid "switching too much" for evaluation. Therefore, Strategies not included, ambiguous degree and ambiguous Essential, established standard weights and human Each to match the types of belief the weights of factors/ additives and attain each e-studying software rating [17].Many decisions are concerning imprecision seeing that desires, constraints, and viable movements aren't exactly in description the end result of choice making in uncertain surroundings is enormously laid low with subjective judgments which are indistinct and imprecise. To resolve this kind of imprecision problem, fuzzy set theory was first introduced via as a mathematical way to represent and take care of vagueness in selection making. In fuzzy logic, every number among zero and 1 shows a partial truth, whereas crisp units correspond to binary good judgment to be able to make amends for the insufficiency of choice making, this research affords a gray possibility degree to pick out the appropriate answer based on gray numbers [18]. This have a look at proposes a modern version to become aware of the Divisions liable for the negative overall performance of the format task. The middle of the version combines the glad significance evaluation (sia) with the choice making trial and evaluation laboratory technique (dematel). This dematel-based completely version is then carried out to the real-international layout task of a excessive-tech facility in Taiwan. The relaxation of this paper is organized as follows. Section 2 evaluations the contemporary associated research. Section 3 introduces the stairs in the proposed version, while section 4 elucidates the background of the case assignment [19].

\section{Critical Success Factors}

Critical success elements (additionally called key results regions or kras) Parts of your business or endeavor Are important to accomplish it. Finding and talking about csfs in your organization Confirming your company or undertaking remains targeted on what desires to be accomplished to reap fulfillment important success element analysis the use of the proposed technique to measure the connection between assessment elements, it is vital to invite specialists who come from exceptional operating backgrounds to make assessments in phrases of influences and dating amongst factors. So we discover 3 professionals, who come from a set named reliability and hazard engineering and control in Vanderbilt university, use, an workplace of disaster assistance of neighborhood government of Chongqing, china, and an emergency management 
employer in Chongqing, china, respectively. They give their linguistic checks about the impact, which elements have direct impacts on each deferent's [20].Generally speak me, factors in impact organization are tend to be without problems impacted via others, which makes effect factors unsuitable to be a crucial achievement aspect. Nevertheless, it is still vital to discuss impact factors to find out the characteristic of each aspect. So, one impact aspect out of eleven is recognized as a restaurant after similarly evaluation of impact elements the concept "essential fulfillment elements" (csfs) Introduced with the aid of csfs and first utilized in undertaking management studies. Generally it's miles broadly used in numerous contexts like company management and the relaxation of this paper is prepared as follows. Part 2 briefly evaluations the literature on emergency control and critical fulfillment aspect (csf). Section 3 offers the proposed technique for identifying csfs [21].Previous studies have used a variety of methods to demonstrate correlations between criteria affecting bpm. A case study was conducted in the banking sector to find out the key success factors. Provide a framework that integrates and builds the essential factors that make up the whole of PPM. The complete structure of the success factors, It also provides relevant guidelines for achieving success in BPM. In these studies, relative and standard inaccuracies and poor descriptive relationship assessments there were. For any strategic project, invention or product, these strategies have important success factors, It serves as the basis for the success of top managers in field research organizations, and supports this assumption that high management support is essential [22]. The main purpose of this study is to influence the sustainability of project management efforts in construction Establishing an effective approach to estimating critical success factors (csfs). Therefore, this study will identify and classify those csfs taking into account the stability factors undertook a thorough literary review. Substantial amount of research has previously studied csfs in construction factors. Without a general understanding of a project's csfs, it is almost impossible to effectively manage and control project performance. Therefore, it is important for project managers to determine appropriate and critical success criteria in order to have a clear and measurable structure [23].Study of critical success factors (csfs) Decision makers have their own information needs Created as a means of identification, and thus Information systems can be created to meet those needs.. Rockmart defined csfs as the components needed to achieve a goal. However real world, all components factors Improvement is not possible at once due to limited resources? To solve this problem, it is important the relationship between factors To identify and the key success factor [24].

\section{Analytic Network Process}

Analytical Network Process (anp) is analysis Much of the hierarchical process Common format (ahp) used in multi-scale decision analysis. Both then use a system of pairing comparisons to measure the weight of the components of the structure, and at the end the alternatives can be sorted. The relatively new mcdm systematic analysis network process (anp) is a mathematical theory, It's all sorts Can be dealt with properly dependencies. For example, many highly educated staff Management Science or Functional in Graduate School Learned analytical methods of research, and more some of them are in the process of decision making or Show more interest in the process. Therefore, highly educated A comprehensive mcdm system is required to meet such needs of employees [25] Obscure anp and obscure tops is to evaluate inexperienced suppliers. Internal dependencies at the hassle shape have been handled with the aid of 681 obscure dematel techniques. The total dating matrix became derived from the 682 demat machine, and it turned into placed in the perfect columns at the weightless brilliant matrix. The remainder of the extraordinary matrix is filled with the weights of the ambiguous pair contrast matrix of the ambiguous anp machine. Ambiguous anp, and ambiguous records envelope analysis on Performance measurement of generally conducted pharmaceutical companies. That the perspectives of symmetrical scorecards are interdependent The demat method was used to capture. Comparative Significance the standards become decided via the ambiguous anp technique [26].This paper makes use of anp and dematel to create and analyze a strategic map. The use of each mcdms has by no means been seen before within the literature. The combination of Anp and dematel isn't new, but the method supplied right here isn't the same as the existing literature. Developed an mcdm model referred to as Moisture that combines the 2 approaches. Dematel is used to obtain the overall have an impact on matrix (t) for clusters and anp is used to achieve the extremely good matrix relative to the nodes, It is weighed by using the outcomes of the dematel. To choose an outsourcing company and to pick renewable electricity sources Fuzzy anp to create a dematel-anp method. Finally, an outstanding literary observe of the composition of anp and dematel is executed, they offer a hard and fast of methods wherein each methods are connected. It is critical to note that none of the above considered the technique used in this have a look at [27].The ambiguous anp pattern within each cluster or key criterion, and according to the relative relationships, is of relative importance Derived from dematel to create weights. The Super Matrix is then designed and those weights are placed on the Super Matrix. This process normalizes the super matrix and the weights are integrated and stabilized Up integrates into the solution by elevating the Super Matrix to a sufficiently large force. This new team range is called the Super Matrix, which specifies the relevant priorities for each alternative [28].In this study, methods fuzzy dematel, fuzzy anp and fuzzy tops To assist in strategic decisions such as gscm Proposes an innovative hybrid analysis approach based on Ambiguous anp and ambiguous custom ranking system (Prometheus) method for enrichment estimates. In their study, evaluation criteria Pollution Control, Green Process Management Environment and assembly management, environmental costs Determined as green product and green film. Hazardous waste transport Companies rating was introduced using a two-step ambiguous-ahp and tops method. Health and safety, quality of service, complementary service, economic factors, service time, human health and environmental protection standards are the criteria [29]. An overview of the proposed version is given in Figure 1. It combines if- dematel and if-anp strategies. Accordingly, the evaluation standards and the options to be had to pick out from might be determined first. This is performed with the help of expert evaluations and a detailed literary evaluation. The organization decision is then requested from the dms group. Based at the statistics received from dms, capability criteria affecting the selection-making goal are decided. The comparative criterion become then decided on, which became vital to prioritize the standards and examine the options. In the next step, the interdependence between the criteria turned into hooked up. Amp rankings in the correct column. A Partition of a Super Matrix Is described as the group, wherein each 
subgroup has relationships between two clusters. Local preference vectors are given inside the corresponding columns in the Super Matrix [30].

\section{Conclusion}

In order to better implement the capacity building of their global managers, our proposed company to evaluate and classify eight iqs Shows that the vague dimmatol method was used. Therefore, the skills needed to better implement the skill development of global managers we proposed a vague dematol method for achieving segmentation. Our proposed method is to use both linguistic variables and ambiguous integration method by successfully expanding the dematal system So that vague and erroneous judgments can be effectively dealt with. Green supply chain management Is product design Material proof and selection, Distribution chain including production processes and distribution As the integration of environmental thinking in management Is defined. Then the final Product end product management and it's for consumers Useful life. Green supply chain or fixed network Is a function of reducing environmental impact Management method and optimization approach are defined as. The life cycle of green materials, from the raw material to the final product. Decision testing and evaluation laboratory (Tim Adele) The technique was first introduced in 1976 by Fondola and Used by Caps. Demetal has become a very popular system in Japan, because it is a pervasive technique, it is all intertwined Reason and evaluating effect relationships can create. In each configuration model. The proposed decision- making method is used to analyze the internal barriers to the reproduction process. Important Success Factors (also known as Key Decision Areas or Crosses) are critical to the success of your business or project. What can be done to achieve the success of using the proposed method Important Success Factor Analysis to measure the relationship between evaluation factors? To make sure your business or project is focused on, you need to find and contact the csfs in your organization. People Different task backgrounds make estimates from based on the effects and relationship between factors. Analytical Network Process (anp) is the analysis step much of the process Common format (ahp) used in multi-scale decision analysis. Both Then measure the weight of the components of the structure, and eventually alternatives Use the system of comparisons to connect can be sorted.

\section{Reference}

1. Wu, Wei-Wen, and Yu-Ting Lee. "Developing global managers' competencies using the fuzzy DEMATEL method." Expert systems with applications 32, no. 2 (2007): 499-507.

2. Si, Sheng-Li, Xiao-Yue You, Hu-Chen Liu, and Ping Zhang. "DEMATEL technique: A systematic review of the state-of-the-art literature on methodologies and applications." Mathematical Problems in Engineering 2018 (2018).

3. Li, Ya, Yong Hu, Xiaoge Zhang, Yong Deng, and SankaranMahadevan. "An evidential DEMATEL method to identify critical success factors in emergency management." Applied Soft Computing 22 (2014): 504-510.

4. Feng, Changli, and Ruize Ma. "Identification of the factors that influence service innovation in manufacturing enterprises by using the fuzzy DEMATEL method." Journal of Cleaner Production 253 (2020): 120002.

5. Büyüközkan, Gülçin, and SezinGüleryüz. "An integrated DEMATEL-ANP approach for renewable energy resources selection in Turkey." International journal of production economics 182 (2016): 435-448.

6. Chang, Betty, Chih-Wei Chang, and Chih-Hung Wu. "Fuzzy DEMATEL method for developing supplier selection criteria." Expert systems with Applications 38, no. 3 (2011): 1850-1858.

7. Lin, Ru-Jen. "Using fuzzy DEMATEL to evaluate the green supply chain management practices." Journal of Cleaner Production 40 (2013): 32-39.

8. Gandhi, Sumeet, Sachin Kumar Mangla, Pradeep Kumar, and Dinesh Kumar. "Evaluating factors in implementation of successful green supply chain management using DEMATEL: A case study." International strategic management review 3, no. 1-2 (2015): 96-109.

9. Hsu, Chia-Wei, Tsai-Chi Kuo, Sheng-Hung Chen, and Allen H. Hu. "Using DEMATEL to develop a carbon management model of supplier selection in green supply chain management." Journal of cleaner production 56 (2013): 164-172.

10. Govindan, Kannan, and Atanu Chaudhuri. "Interrelationships of risks faced by third party logistics service providers: A DEMATEL based approach." Transportation Research Part E: Logistics and Transportation Review 90 (2016): 177-195.

11. Lin, Kuo-Ping, Ming-Lang Tseng, and Ping-Feng Pai. "Sustainable supply chain management using approximate fuzzy DEMATEL method." Resources, Conservation and Recycling 128 (2018): 134-142.

12. Govindan, Kannan, RoohollahKhodaverdi, and Amin Vafadarnikjoo. "Intuitionistic fuzzy based DEMATEL method for developing green practices and performances in a green supply chain." Expert Systems with Applications 42, no. 20 (2015): 7207-7220.

13. Xia, Xiqiang, Kannan Govindan, and Qinghua Zhu. "Analyzing internal barriers for automotive parts remanufacturers in China using grey-DEMATEL approach." Journal of Cleaner Production 87 (2015): 811-825.

14. Tzeng, Gwo-Hshiung, Wen-Hsien Chen, Rachung Yu, and Meng-Lin Shih. "Fuzzy decision maps: a generalization of the DEMATEL methods." Soft Computing 14, no. 11 (2010): 1141-1150.

15. Vujanović, Davor, Vladimir Momčilović, NebojšaBojović, and Vladimir Papić. "Evaluation of vehicle fleet maintenance management indicators by application of DEMATEL and ANP." Expert Systems with Applications 39, no. 12 (2012): 10552-10563.

16. Tseng, Ming-Lang, and Yuan Hsu Lin. "Application of fuzzy DEMATEL to develop a cause and effect model of municipal solid waste management in Metro Manila." Environmental monitoring and assessment 158, no. 1 (2009): 519-533.

17. Tzeng, Gwo-Hshiung, Cheng-Hsin Chiang, and Chung-Wei Li. "Evaluating intertwined effects in e-learning programs: A novel hybrid MCDM model based on factor analysis and DEMATEL." Expert systems with Applications 32, no. 4 (2007): 1028-1044. 
18. Tseng, Ming-Lang. "A causal and effect decision making model of service quality expectation using grey-fuzzy DEMATEL approach." Expert systems with applications 36, no. 4 (2009): 7738-7748.

19. Wang, Wei-Chih, Yueh-Hua Lin, Chia-Li Lin, Chu-Hsuan Chung, and Ming-Tsung Lee. "DEMATEL-based model to improve the performance in a matrix organization." Expert Systems with Applications 39, no. 5 (2012): 49784986.

20. Li, Ya, Yong Hu, Xiaoge Zhang, Yong Deng, and SankaranMahadevan. "An evidential DEMATEL method to identify critical success factors in emergency management." Applied Soft Computing 22 (2014): 504-510.

21. Zhou, Quan, Weilai Huang, and Ying Zhang. "Identifying critical success factors in emergency management using a fuzzy DEMATEL method." Safety science 49, no. 2 (2011): 243-252.

22. Bai, Chunguang, and Joseph Sarkis. "A grey-based DEMATEL model for evaluating business process management critical success factors." International Journal of Production Economics 146, no. 1 (2013): 281-292.

23. Mavi, Reza Kiani, and Craig Standing. "Critical success factors of sustainable project management in construction: A fuzzy DEMATEL-ANP approach." Journal of cleaner production 194 (2018): 751-765.

24. Han, Yuzhen, and Yong Deng. "An enhanced fuzzy evidential DEMATEL method with its application to identify critical success factors." Soft computing 22, no. 15 (2018): 5073-5090.

25. Wu, Wei-Wen. "Choosing knowledge management strategies by using a combined ANP and DEMATEL approach." Expert systems with applications 35, no. 3 (2008): 828-835.

26. Gölcük, İlker, and AdilBaykasoğlu. "An analysis of DEMATEL approaches for criteria interaction handling within ANP." Expert Systems with Applications 46 (2016): 346-366.

27. Quezada, Luis E., Héctor A. López-Ospina, Pedro I. Palominos, and Astrid M. Oddershede. "Identifying causal relationships in strategy maps using ANP and DEMATEL." Computers \& Industrial Engineering 118 (2018): 170179.

28. Uygun, Özer, Hasan Kaçamak, and ÜnalAtakanKahraman. "An integrated DEMATEL and Fuzzy ANP techniques for evaluation and selection of outsourcing provider for a telecommunication company." Computers \& Industrial Engineering 86 (2015): 137-146.

29. Büyüközkan, Gülçin, and GizemÇifçi. "A novel hybrid MCDM approach based on fuzzy DEMATEL, fuzzy ANP and fuzzy TOPSIS to evaluate green suppliers." Expert Systems with Applications 39, no. 3 (2012): 3000-3011.

30. Büyüközkan, Gülçin, SezinGüleryüz, and BirsenKarpak. "A new combined IF-DEMATEL and IF-ANP approach for CRM partner evaluation." International Journal of Production Economics 191 (2017): 194-206.

31. Gadde Mehar Chaitanya, M.P.Jenarthanan, C. Sathiyaraj, A Review on Glass fibre Reinforced Composites with Different Matrix, REST Journal on Emerging trends in Modelling and Manufacturing Vol: 7(1), 2021, 18-24.

32. R. Kurinjimalar, S. Vimala, M. Silambarasan, S. Chinnasami, A Review on Coir fibre Reinforced Composites with Different Matrix, REST Journal on Emerging trends in Modelling and Manufacturing Vol: 7(2), 2021, 25-32.

33. P. K. Chidambaram, Dr. Amol Lokhande, Dr. M. Ramachandran, Vimala Saravanan, Vidhya Prasanth, A Review on Biodiesel Properties and Fatty acid composites, REST Journal on Emerging trends in Modelling andManufacturing Vol: 7(3), 2021, 87-93.

34. P.K.Chidambaram, Dr. Amol Lokhande, Dr. M. Ramachandran, M. Nathiya, G. Mathivanan, A study on Carbon Fiber Based Polymer Rein Force composites, REST Journal on Emerging trends in Modelling andManufacturing Vol: 7(3), 2021, 94-100.

35. Mane, Manashree, and Vaishnavi Narreddy. "Estimation of sexual dimorphism using epidermal ridge breadth measurements in Indian population." International Journal of Medical Toxicology \& Legal Medicine 24, no. 1and2 (2021): 242-248.

36. Dhaarani, S. D., Sona Ponnuswamy, and Manashree Mane. "A Study on Impact of Pellets on Different Targets-A Preliminary Study." Medico-Legal Update 21, no. 4 (2021).

37. Anvitha, E. D., and Manashree Mane. "Forensic significance of fibre transfer through weapon thrust."

38. Sreekumar, Krishnendhu, Rohith Krishna, Sheetal Rajan, and Manashree Mane. "A study on the transfer and persistence of glass fragments on various fabrics-a forensic perspective."

39. Umapathi, and Ramaraj. "PERFORMANCE EVALUATION OF DSR ROUTING PROTOCOL UNDER DIVERGING AND CONVERGING NODES." IIOAB JOURNAL 7, no. 9 (2016): 269-275.

40. Umapathi, N., and N. Ramaraj. "Wireless Adhoc Telemedicine System: Improving Network Performance for Multimedia Data." Journal of Medical Imaging and Health Informatics 6, no. 8 (2016): 1944-1948.

41. Krishna, G. Murali, G. Karthick, and N. Umapathi. "Design of Dynamic Comparator for Low-Power and HighSpeed Applications." In ICCCE 2020, pp. 1187-1197. Springer, Singapore, 2021.

42. Umapathi, N., G. Murali Krishna, and Lingala Srinivas. "A Comprehensive Survey on Distinctive Implementations of Carry Select Adder." In 2021 4th Biennial International Conference on Nascent Technologies in Engineering (ICNTE), pp. 1-5. IEEE, 2021.

43. Umapathi, N., Saiteja Sabbani, and S. Poovarasan. "Person Location Tracking Using Global Positioning System and ESP8266 with Internet of Things." In Futuristic Communication and Network Technologies, pp. 211-217. Springer, Singapore, 2022.

44. Umapathi, N., and Saiteja Sabbani. "An Internet of Things (IoT)-based Approach for Real-Time Kitchen Monitoring Using NodeMCU 1.0." In Futuristic Communication and Network Technologies, pp. 35-43. Springer, Singapore, 2022.

45. Balaji, V., V. Duraisamy, and N. Umapathi. "Cluster based packet loss prediction using packet lost segment in wireless network." In 2010 IEEE International Conference on Computational Intelligence and Computing Research, pp. 1-4. IEEE, 2010. 
46. Kshirsagar, P., \& Akojwar, S. (2016). Hybrid Heuristic Optimization for Benchmark Datasets. International Journal of Computer Application, 146.

47. Kshirsagar, Pravin R., Sudhir G. Akojwar, and Nidhi D. Bajaj. "A hybridised neural network and optimisation algorithms for prediction and classification of neurological disorders." International Journal of Biomedical Engineering and Technology 28, no. 4 (2018): 307-321.

48. Kshirsagar, P., and S. Akojwar. "Optimization of BPNN parameters using PSO for EEG signals." Adv. Intell. Syst. Res 137 (2017): 385-394.

49. Kshirsagar, Pravin, and Sudhir Akojwar. "Novel approach for classification and prediction of non linear chaotic databases." In 2016 International Conference on Electrical, Electronics, and Optimization Techniques (ICEEOT), pp. 514-518. IEEE, 2016.

50. Kshirsagar, P., \& Akojwar, S. (2015). Classification \& Detection of Neurological Disorders using ICA \& AR as Feature Extractor. Int. J. Ser. Eng. Sci. IJSES, 1(1).

51. Kshirsagar, PRAVIN R., SUDHIR G. Akojwar, and R. A. M. K. U. M. A. R. Dhanoriya. "Classification of ECGsignals using artificial neural networks." Researchgate. net (2017).

52. Kshirsagar, Pravin, Nagaraj Balakrishnan, and Arpit Deepak Yadav. "Modelling of optimised neural network for classification and prediction of benchmark datasets." Computer Methods in Biomechanics and Biomedical Engineering: Imaging \& Visualization 8, no. 4 (2020): 426-435.

53. Akojwar, SUDHIR G., and Pravin Kshirsagar. "A Novel Probabilistic-PSO Based Learning Algorithm for Optimization of Neural Networks for Benchmark Problems." In WSEAS International conference on Neural Network-2016, Rome, Italy (Published in WSEAS Electronic Transaction). 2016.

54. Kshirsagar, Pravin, and Dr Sudhir Akojwar. "Classification and Prediction of Epilepsy using FFBPNN with PSO." In IEEE International Conference on Communication Networks, vol. 17. 2015.

55. Kshirsagar, Pravin, Vijetalaxmi Pai, and Sudhir Akojwar. "Feature Extraction of EEG Signals using Wavelet and Principal Component analysis." In National Conference On Research Trends In Electronics, Computer Science \& Information Technology And Doctoral Research Meet, Feb 21st \& 22nd.

56. Katakam, Lakshmi Narasimha Rao, Thirupathi Dongala, and Santhosh Kumar Ettaboina. "Novel stability indicating UHPLC method development and validation for simultaneous quantification of hydrocortisone acetate, pramoxine hydrochloride, potassium sorbate and sorbic acid in topical cream formulation." Talanta Open 1 (2020): 100004.

57. Dongala, Thirupathi, Naresh Kumar Katari, Santhosh Kumar Ettaboina, Anand Krishnan, Murtaza M. Tambuwala, and Kamal Dua. "In vitro Dissolution Profile at Different Biological pH Conditions of Hydroxychloroquine Sulfate Tablets Is Available for the Treatment of COVID-19." Frontiers in Molecular Biosciences 7 (2021): 441.

58. Katakam, Lakshmi Narasimha Rao, Santhosh Kumar Ettaboina, and Thirupathi Dongala. "A simple and rapid HPLC method for determination of parabens and their degradation products in pharmaceutical dosage forms." Biomedical Chromatography (2021): e5152.

59. Katakam, Lakshmi Narasimha Rao, Thirupathi Dongala, and Santhosh Kumar Ettaboina. "Quality by design with design of experiments approach for development of a stability-indicating LC method for enzalutamide and its impurities in soft gel dosage formulation." Biomedical Chromatography 35, no. 5 (2021): e5062.

60. Ettaboina, Santhosh Kumar, Komalatha Nakkala, and K. S. Laddha. "A Mini Review on SARS-COVID-19-2 Omicron Variant (B. 1.1. 529)." SciMedicine Journal 3, no. 4 (2021): 399-406.

61. Yenda, Parvateesam, Naresh Kumar Katari, Thirupathi Dongala, Govind Vyas, Lakshmi Narasimha Rao Katakam, and Santhosh Kumar Ettaboina. "A simple isocratic LC method for quantification of trace-level inorganic degradation impurities (ferricyanide, ferrocyanide, nitrite, and nitrate) in sodium nitroprusside injection and robustness by quality using design approach." Biomedical Chromatography (2021): e5269.

62. Katakam, Lakshmi Narasimha Rao, Santhosh Kumar Ettaboina, and Vishnu Murthy Marisetti. "Development and validation of LC-MS method for the determination of heptaethylene glycol monomethyl ether in benzonatate bulk drugs." Biomedical Chromatography 35, no. 7 (2021): e5096.

63. Dheenadhayalan, V. "An Analysis of Financial Health of Select Indian Bulk Drugs and Formulations Companies* Mrs. R. Selvi."

64. Banana, K. R. I. S. H. N. A., and R. V. Chepuri. "Role of recovery channels in managing non-performing assets in scheduled commercial banks." International Journal for Innovative Research in Multidisciplinary Field 2, no. 10 (2016): 355-359.

65. Dheenadhayalan, V., and R. Devianbarasi. "Financial health of cooperative sugar mills-a case study of NPKRR cooperative sugar mill ltd." Indian Cooperative Review 46, no. 3 (2009): 192-197.

66. Dheenadhayalan, V., and D. Rajaprabu. "Loan Assets in New Private Sector Banks in India." Asian Journal of Management 5, no. 3 (2014): 347-353.

67. Dheenadhayalan, V. "Impact of E-Commerce on the Changes in Consumer's Buying Behaviour in Malappuram District." Annals of the Romanian Society for Cell Biology (2021): 3441-3452.

68. Dheenadhayalan, V., and R. Shanmuga Priya. "Influencing Factors on Purchase Decision of Women Two-Wheeler Users." Annals of the Romanian Society for Cell Biology (2021): 3430-3440.

69. Dheenadhayalan, V. "An Analysis of Financial Health of Select Indian Bulk Drugs and Formulations Companies* Mrs. R. Selvi."

70. DHEENADHAYALAN, V. "Impact Of Training And Development On Performance Appraisal Of Employees In Information Technology Companies A Study With Reference To Chennai City." 
71. Dheenadhayalan, V. "Mudra-A Tool for Uplifting Micro Enterprises in India." International Journal in Management \& Social Science 4, no. 12 (2016): 235-246.

72. Gupta, Devansh. "Foreign Direct Investment in India: An Overview." International Journal of Education and Management Studies 7, no. 2 (2017): 108-115.

73. Chaudhari, Rakesh, Riddhish Parekh, and Asha Ingle. "Reliability of dissimilar metal joints using fusion welding: A Review." In International Conference on Machine Learning, Electrical and Mechanical Engineering (ICMLEME: 2014).-2014. 2014.

74. Tibadia, Rajkumar, Koustubh Patwardhan, Dhrumil Shah, Dinesh Shinde, Rakesh Chaudhari, and Kanak Kalita. "Experimental investigation on hole quality in drilling of composite pipes." Transactions of the Canadian Society for Mechanical Engineering 42, no. 2 (2018): 147-155.

75. Kalita, Kanak, Rakesh Chaudhari, and M. Ramachandran. "Mechanical characterization and finite element investigation on properties of PLA-jute composite." International Journal of Computer Applications 123, no. 13 (2015).

76. Chaudhari, Rakesh, Asha Ingle, and Kanak Kalita. "Stress analysis of dissimilar metal weld between carbon steel and stainless steel formed by transition grading technique." Materials Today: Proceedings 2, no. 4-5 (2015): 16571664.

77. Kittur, Jeevan, Bhavya Desai, Rakesh Chaudhari, and Praveen Kumar Loharkar. "A comparative study of EMI shielding effectiveness of metals, metal coatings and carbon-based materials." In IOP Conference Series: Materials Science and Engineering, vol. 810, no. 1, p. 012019. IOP Publishing, 2020.

78. Chaudhari, Rakesh, and Asha Ingle. "Experimental investigation of dissimilar metal weld of SA335 P11 and SA312 TP304 formed by gas tungsten arc welding (GTAW)." Transactions of the Indian Institute of Metals 72, no. 5 (2019): 1145-1152.

79. Chaudhari, Rakesh, Asha Ingle, and Kanak Kalita. "Tribological Investigation of Effect of Grain Size in 304 Austenitic Stainless Steel." Transactions of the Indian Institute of Metals 70, no. 9 (2017): 2399-2405.

80. Chaudhari, R., P. K. Loharkar, and A. Ingle. "Applications and challenges of arc welding methods in dissimilar metal joining." In IOP Conference Series: Materials Science and Engineering, vol. 810, no. 1, p. 012006. IOP Publishing, 2020.

81. Chaudhari, Rakesh, Asha Ingle, and Kanak Kalita. "Experimental Investigation of Correlation of Grain Size and Mechanical Properties in 304 Stainless Steel." Materials Focus 5, no. 5 (2016): 440-445. 